\title{
Environmental envelopes — identifying limits affecting ecosystem management after mining
}

\author{
M.V. Fey Centre for Land Rehabilitation, School of Earth and Environment, The University of Western \\ Australia, Australia
}

A.J. Mills Department of Soil Science, Stellenbosch University, South Africa

\begin{abstract}
Environmental envelopes are so named because they depict how parameters of interest are shaped by their environment. They are boundary lines separating the observed world from an imaginary one. Quantile regression enables us to determine their position objectively. Once located, the envelope enables us to separate the range(s) of a determinant variable over which some variable of interest (relating to biological performance, for example) is inevitably minimal from the range over which it is potentially at its maximum value. Thus, in ecosystem management, which is critical to the sustainability of land use after mine closure, we can identify ways in which plant cover and species diversity are affected by environmental variables such as soil infiltrability even under conditions when other determinants are not kept constant. Recognising this paradigm allows restoration ecologists to reduce their dependence on factorial field experiments for discovering suitable methods of mine site rehabilitation. It is also applicable to discovering relationships between abiotic variables in large data sets, such as that between routinely measured soil properties and ones which are not readily determined but of which knowledge is critical in determining appropriate restoration practices after mining. If combined with the diagnosis and recommendation integrated system (DRIS) principles and enough spade work to build a reliable and comprehensive database, it could revolutionise management by generating norms in terms of which the factors affecting ecosystem function can be ranked in order of limiting importance.
\end{abstract}

\section{Introduction}

Post mining restoration typically aims at recreating a stable ecosystem so that mine closure is sustainable. Research is usually carried out during mining to discover the best way of restoring, as closely as practicable, the original condition of the mine site. Usually this takes the form of field trials, supported by laboratory and glasshouse research, designed to test and compare the effects of various treatments expected to benefit the restoration process. Often such trials are only introduced once an initially prescribed method of rehabilitation is found not to work satisfactorily. Although factorial experiments are valuable and even essential, they are cumbersome and expensive and at best can give only a rough indication of the ideal conditions for rehabilitation. What is needed is a consideration of all the factors likely to affect ecosystem recovery in a way that allows them to be ranked in order of priority. In this paper the authors aim to show how principles developed in agriculture are beginning to find application in ecological research and could provide an important tool for the long-term management and monitoring of mine site rehabilitation.

\section{Origin of the environmental envelope concept}

An agronomic paradigm shift began to take place in the rubber plantations of Vietnam in the late 1950s which has now established itself, albeit tenuously, on the world stage of plant nutrition research. French scientist E.R. Beaufils developed a system, which he termed physiological diagnosis (PD), for assessing the nutritional requirements of rubber trees by analysing the latex and developing norms based on nutrient balance according to which the major plant nutrients could be ranked in order of limiting requirement. In the 1960 s, Beaufils moved to South Africa and continued his work on maize, sugar cane and other crops, making use of foliar and soil analyses, as well as a quantitative assessment of other factors affecting crop yield, to develop norms in an expanded scheme for which he coined the acronym DRIS (Beaufils, 1973). For a few years he teamed up with M.E. Sumner at the University of Natal and thereafter practised as an agricultural 
consultant after Sumner had moved to the USA in the mid 1970s. It was Sumner's subsequent publications that put DRIS on the map from an agronomic research point of view. Beaufils put the principles into practice by developing a growing, comprehensive database for a variety of crops and using DRIS as an advisory tool for farmers. He continued to practise as a consultant until his death in the mid 1990s. His views were controversial among mainstream agronomic researchers for he was severely critical of the blinkered view of crop requirements provided by factorial experimentation. Like all paradigm shifters he had his fair share of detractors.

What is the essence of DRIS as Beaufils conceived it? Firstly, you need a very large data set, which can derive just as well from commercial production lands as from experimental plots; thousands rather than hundreds of sites will make a difference - the more the merrier. Secondly, you need to consider all (or as many as possible) of the factors, both controllable and uncontrollable, that have the potential to affect crop yield or at least are related to it. Once a reasonable database has been established, norms for the crop in question can provisionally be established then continually refined. These norms identify optimal values, in terms of yield, for expressions (usually calculated ratios) which relate the intensities of one factor to another. Having established these norms, any given site can then be assessed as follows: the required data are assembled, ratios are calculated for all the factors being considered and these are then used to calculate an index which quantifies the extent to which any one factor is deficient or excessive relative to all other factors. The index for a factor is calculated as a mean deviation from the optimum of all the ratio expressions in which that factor appears. The negative or positive values of the DRIS indices allow a quantitative ranking to be made of the factors in terms of their importance in limiting yield. So much for the D in DRIS; there is a conceptual affinity here with the Sprengel-Liebig Law of the Minimum. As far as the R in DRIS is concerned, Beaufils was always at pains to point out that no recommendation can be of any value without an accurate diagnosis. His database allowed him to take an historical look at responses to specific recommendations formulated from his diagnoses and to make adjustments based on experience.

The main disadvantage of DRIS lies in one of its advantages. Because it is based on such a comprehensive consideration of yield-related factors and so wide a coverage of growing conditions in the field, the cost and time required to build DRIS to a reliable level of detail is potentially inhibitory given the usual manner of research funding. This is possibly why, despite a continuing modern sprinkling of international research reports exploiting DRIS principles for a variety of crop and tree species, the DRIS approach has failed to supplant conventional factorial experimentation as a basis for improving crop production. Perhaps with the current emphasis on sustainability and soil health in agriculture there may yet be a place for DRIS in mainstream agronomic thought. What this paper is intended to convey is that some of the principles of DRIS are well suited to application in a variety of other fields, notably soil chemistry, ecology and environmental science.

In particular, the so-called boundary line approach (Walworth et al., 1986; Walworth and Sumner, 1987) avoids the sterility associated with conventional regression analysis of biological response to a determinant variable when many other determinants are simultaneously involved. In separating actual (observed) from imaginary (never observed) behaviour, the boundary line provides a method for identifying ranges of the determinant variable over which it exerts the strongest and weakest constraints on the parameter in question (such as biological performance). More recently the principle has found application in ecological studies (Cade and Noon, 2003; Schröder et al., 2005) based on a quantile regression (QR) method (Koenker and Hallock, 2001) for delineating the boundary line. For some time the QR approach has been a central one in risk assessment using extreme value theory (EVT) (Taylor, 2008). In the research reviewed here, where QR was used to determine boundary lines, the authors have often been inclined to use the term environmental envelope because it subsumes the notion of a multi-factorial milieu or set of circumstances impinging on the property or parameter of interest (Figure 1).

\section{Case histories relevant to mine closure}

In this section, some examples of environmental envelopes that are of direct or indirect interest in a mine closure context are reviewed. These relate to vegetation and ecosystem function as well as to environmental quality. 


\subsection{Vegetation cover and restoration}

As a means of understanding the contribution of soil properties to biodiversity and ecosystem function, a method has been developed for assessing the rainwater infiltration behaviour of soils which circumvents laborious rainfall simulation tests and allows large numbers of soil samples to be evaluated cheaply in the laboratory (Mills and Fey, 2004). In testing this method on more than 500 soil samples from arid regions of southern Africa (Mills et al., 2006) some interesting relationships emerged that might otherwise have remained undiscovered. Prediction of infiltration was most certain from texture, especially water-dispersible silt percentage, water-dispersible clay percentage, very fine sand and medium sand. Chemical properties such as EC, Na status, organic $\mathrm{C}$ and clay mineralogy were less clearly related to infiltrability than was texture, and envelopes constructed using quantile regression revealed a probable skeletal role of medium and fine sand fractions in shaping pores and a plasmic (mobile) role of finer fractions in blocking pores. Noteworthy was an apparent switch in role from skeletal to plasmic at a particle diameter of about $0.1 \mathrm{~mm}$, i.e. between fine and very fine sand.

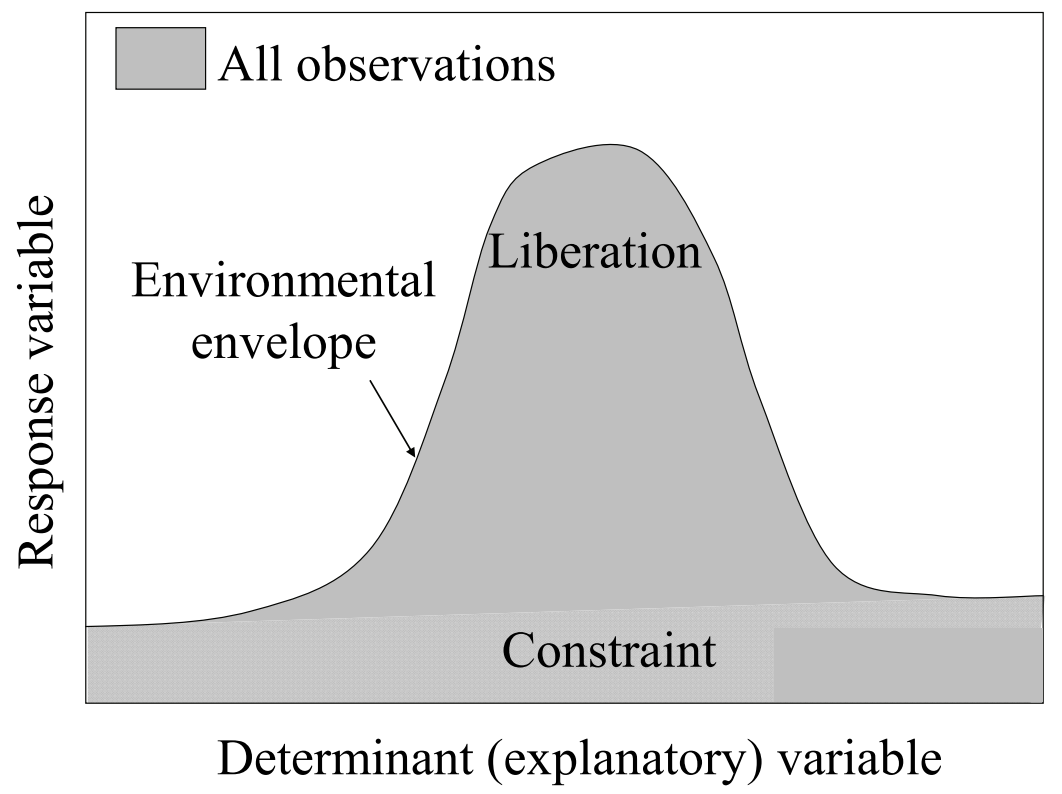

Figure 1 Concept of the environmental envelope as a boundary line enclosing all (statistically valid) measurements of a variable of interest (e.g. plant growth or ecosystem complexity) in relation to the magnitude of one of a number of variables having the capacity to induce a response in the variable of interest. Zones of constraint and liberation beneath the bellshaped curve have explanatory or predictive value in relation to environmental effects

The relationship between vegetation cover in a semi-arid shrubland and soil properties, including infiltrability, was then investigated (Mills et al., 2009). Not only did the aerial cover of some individual plant species show a clear bell-shaped envelope similar to that in Figure 1 when plotted against infiltrability, but biodiversity itself (number of species recorded per unit area) showed a declining envelope with increasing infiltrability, appearing to support the theory that environmental stress, in this case lack of water, is a driver of biodiversity. Data have been assembled (manuscripts in review) from applying the approach to soil respiration studies and to understanding the factors which determine the extent of woody cover in grassy savannas. The approach is also being applied by UWA researchers in the Wungong catchment in the Darling Range, Western Australia, where bauxite mining has been terminated after 40 years and the restored forest vegetation is being managed by thinning to maximise water yield while preserving goals of ecosystem architecture. 


\subsection{Metals in the background}

Herselman et al. (2005) presented information on the levels of several economically important metals in South African soils. Such information is critically important for objectively determining contamination thresholds and is particularly relevant to mine closure. However, if you consider the bioavailable fraction of a metal, it was found that there is often a pattern such as that illustrated for EDTA-extractable $\mathrm{Cu}$ in relation to soil $\mathrm{pH}$ (Figure 2a). This pattern suggests that extractable $\mathrm{Cu}$ values are constrained (inevitably minimal) towards extremes of $\mathrm{pH}$ but liberated (potentially maximal) in between. The envelope for this plot (Figure 2b) was constructed so as to exclude outliers, i.e. the greatest $2.5 \%$ of 86 values in each of 20 segments; this ensures the exclusion of values that could be anomalous either through error or as a result of contamination. Clearly the natural upper limit to bioavailable $\mathrm{Cu}$ in South African soils is considerably higher in near-neutral soils than it is in strongly acidic soils (probably because of low total $\mathrm{Cu}$ concentrations associated with leaching and parent material effects) or alkaline soils (probably because of low $\mathrm{Cu}$ solubility). Similarly revealing relationships were evident (not shown) between several metals and a selection of soil properties including CEC and carbon and clay contents. The range of soil types is so wide and the number of sites so large that it is tempting to consider envelopes such as that in Figure $2 b$ as universal expressions of what is found in nature.
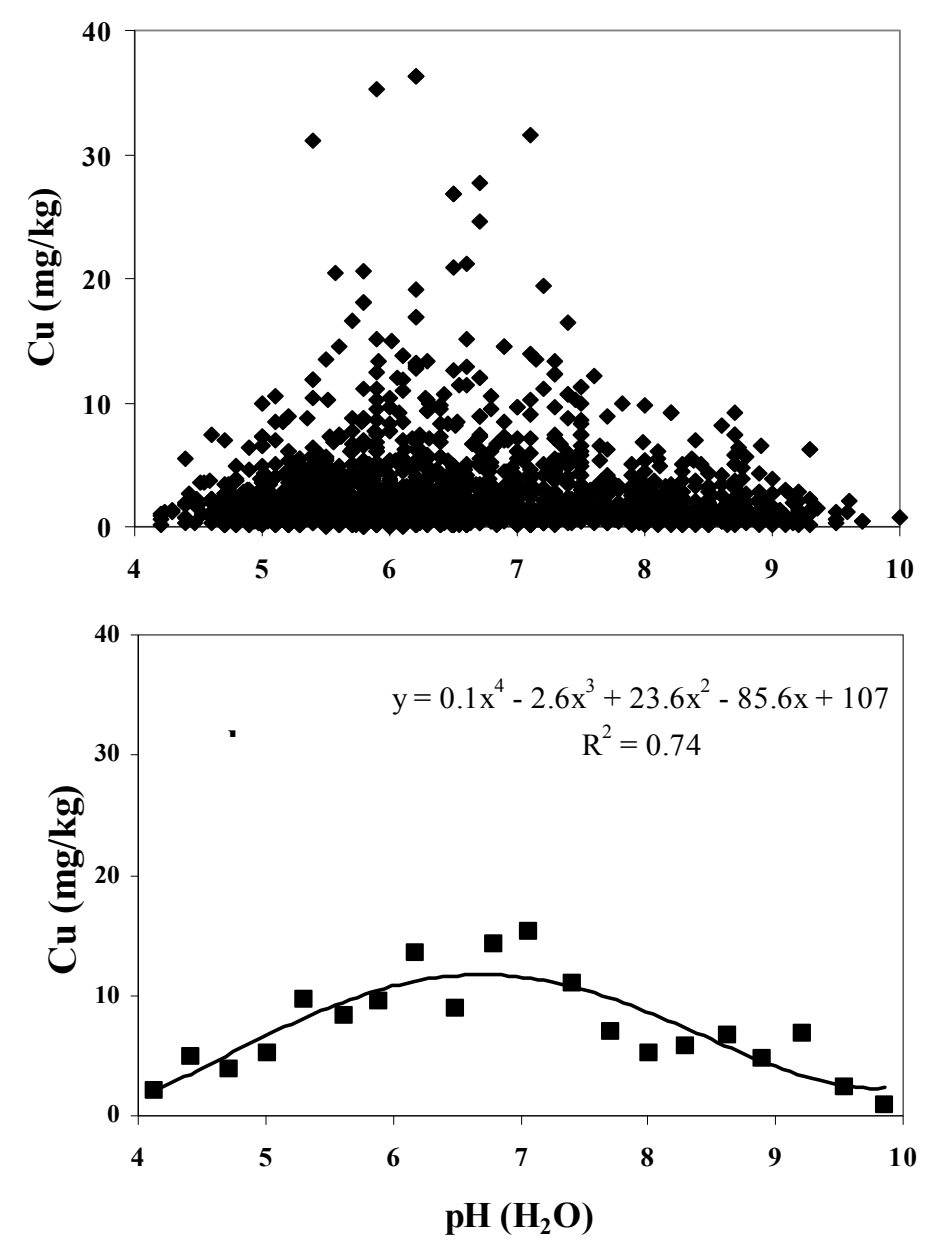

Figure 2 EDTA-extractable copper as a function of soil $\mathrm{pH}$ in representative South African topsoils (a) original data $(n=2135)$; and (b) envelope for the same data derived by segmented quantile regression employing best fit through the 0.975 quantile of 20 equal sized classes (based on data from Herselman, 2007) 


\subsection{Contaminant threat to groundwater}

Another useful application of environmental envelopes has been for interpreting contaminant sorption behaviour in a large group of soils. More than 200 well characterised soils representing a wide range of regolith materials found in southern Africa were investigated using $\mathrm{Cu}$ and $\mathrm{P}$ sorption isotherms to develop a classification system for groundwater vulnerability assessment. The envelope in Figure $3 \mathrm{~b}$ distills that which is essential from the plot of individual soil data in Figure 3a, allowing a routinely measured soil variable such as $\mathrm{pH}$ to be used as a basis for predicting whether copper (and other metal) sorption is going to be inevitably minimal $(\mathrm{pH}<5)$ or potentially maximal $(\mathrm{pH}>7)$ in any newly encountered soil for which $\mathrm{pH}$ and other properties are readily measured. The envelopes allowed the property most restricting sorption to be determined for any soil and also the range of each property to be divided into three classes providing a relative ranking of each soil material. The way the classification works is described in Jovanovic et al. (2006) and Saayman et al. (2007) and is illustrated with example input data in Table 1.
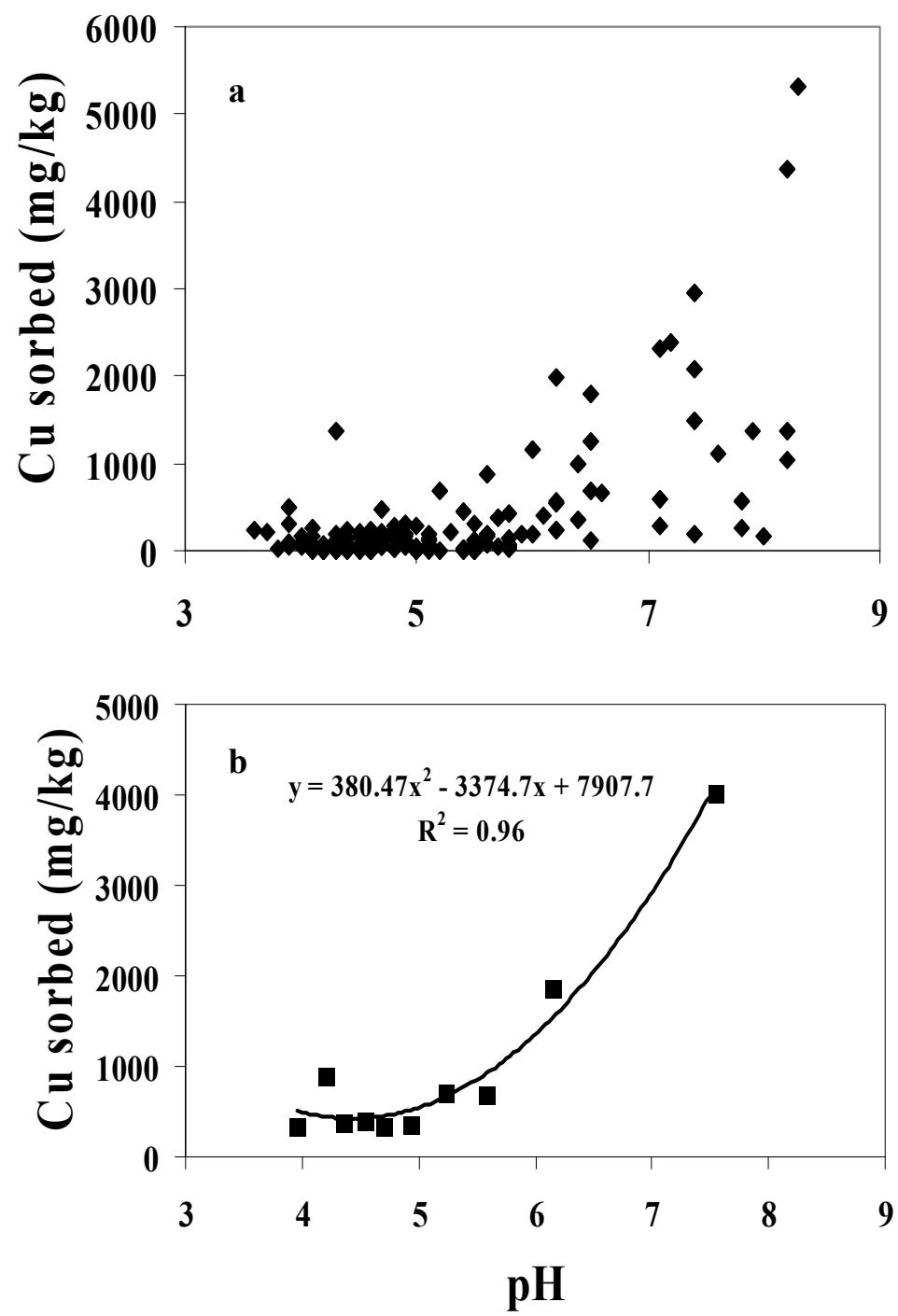

Figure 3 Quantity of $\mathrm{Cu}$ sorbed at an equilibrium $\mathrm{Cu}$ concentration in solution of $1 \mathrm{mg} / \mathrm{L}$, derived from five point isotherms determined experimentally for 200 representative regolith materials in South Africa: (a) shows data for individual soils plotted as a function of $\mathrm{pH}$; (b) shows the envelope constructed by best fit through the 0.95 quantile of 10 equal segments of $\mathbf{n}=\mathbf{2 0}$ (based on data from Mwepu, 2007) 
Table 1 Example of how input values are converted to broad classes of groundwater vulnerability assessment (Saayman et al., 2007) based on five soil properties that govern chemical contamination through sorption of metals, anions or non-polar organic contaminants

\begin{tabular}{llllll}
\hline Input Value for Soil Property & \multicolumn{3}{c}{ Groundwater Vulnerability } \\
& & & Metals & Anions & Organics \\
\hline Al extracted with dithionite & 0.46 & $(\%)$ & & Moderate & \\
Organic C & 1.25 & $(\%)$ & & Moderate & Moderate \\
Clay & 34 & $(\%)$ & Low & Low & \\
Fe extracted with dithionite & 1.93 & $(\%)$ & & Moderate & \\
$\mathrm{pH}\left(\mathrm{CaCl}_{2}\right)$ & 5.0 & & High & Low & \\
$\mathrm{S}$ value: sum of basic cations & 16.3 & $\left(\mathrm{cmol}_{\mathrm{c}} / \mathrm{kg}\right)$ & Moderate & Moderate & \\
\hline
\end{tabular}

\section{Towards developing diagnostic indices for ecosystem management}

Can determinant variables be ranked in order of importance? If we return to consider DRIS (Beaufils, 1973), which provided the original inspiration for the environmental envelope idea, then at least in the arena of crop production the factors that affect yield can be ranked in order of yield-limiting importance by expressing their intensities relative to one another in the form of ratios. Yield is then related to ratio expressions rather than to determinants individually, and the envelope enclosing the data for a suitably large population of production sites reveals a norm which is defined as the optimum value of the ratio expression, i.e. that which most liberates the potential of the crop to yield highly, or conversely, has the least constraining effect on yield (Figure 4).

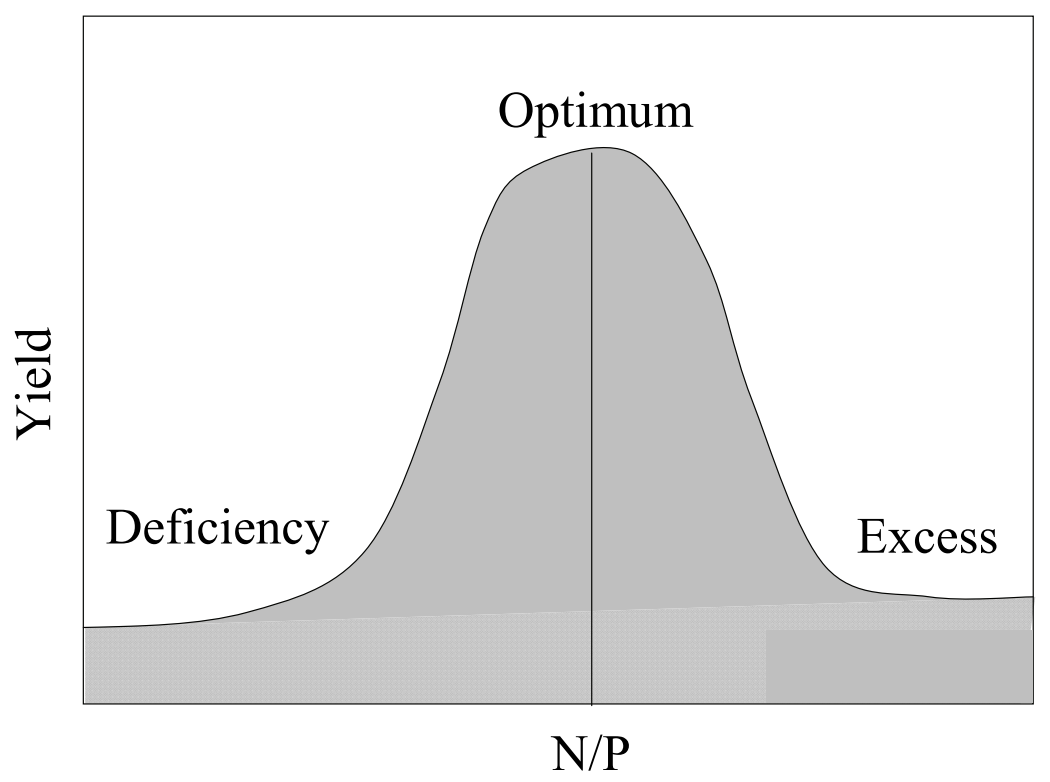

Figure 4 Special case of the principle generalised in Figure 1, in which yield is plotted against the relative intensity (ratio) of a pair of factors known to affect it, in this case concentrations of the two nutrients, $\mathbf{N}$ and $P$

This approach must be pursued exhaustively until as many as possible of the potentially limiting factors have been related to yield in a series of such ratio expressions. Once norms for these expressions have been established for a crop species it is possible to make a diagnosis at new sites by obtaining the necessary data, 
estimating the extent to which the actual value for each expression deviates from the norm for that crop, and then calculating a DRIS index for each factor. This index reflects the average deficiency (negative value) or excess (positive value) of that factor relative to all the others. For the general case in which A, B, C, D....N are growth factors, e.g. nutrient concentrations, the formula for calculating the index for factor $\mathrm{A}$ is:

$$
A \text { index }=[\mathrm{f}(\mathrm{A} / \mathrm{B})+\mathrm{f}(\mathrm{A} / \mathrm{C})+\mathrm{f}(\mathrm{A} / \mathrm{D}) \ldots \ldots+\mathrm{f}(\mathrm{A} / \mathrm{N})] / \mathrm{n}
$$

where:

$$
\mathrm{f}(\mathrm{A} / \mathrm{B})=(1-(\mathrm{a} / \mathrm{b}) /(\mathrm{A} / \mathrm{B})) 100 / \mathrm{CV} \text { if }(\mathrm{a} / \mathrm{b}) /(\mathrm{A} / \mathrm{B})<1
$$

or:

$$
\mathrm{f}(\mathrm{A} / \mathrm{B})=((\mathrm{a} / \mathrm{b}) /(\mathrm{A} / \mathrm{B})-1) 100 / \mathrm{CV} \text { if }(\mathrm{a} / \mathrm{b}) /(\mathrm{A} / \mathrm{B})>1
$$

and where $\mathrm{n}$ is the number of functions containing $\mathrm{A}, \mathrm{a} / \mathrm{b}$ is the norm for the $\mathrm{A} / \mathrm{B}$ ratio and $\mathrm{CV}$ is the coefficient of variation associated with the norm. Division by the CV effectively weights the calculation in favour of those expressions with the greatest capacity for distinguishing between high and low-yielding populations. For factor B the procedure is repeated but with B as either numerator or denominator in which case the relevant function is entered as either a positive or negative value in Equation (1). This process is continued with the remaining factors until all indices are derived.

A consequence of indices being calculated in this way is that some will be positive and others negative and they will always sum to zero. Furthermore, the smaller the numerical sum of indices (i.e. ignoring their sign) the more ideal is the overall balance between factors. Most importantly, however, the magnitude of the indices - from most negative (deficient) to most positive (excessive) - provides a quantitative basis for ranking the factors in terms how limiting they are at the site being investigated (Beaufils, 1973). Much of the literature on DRIS reveals its use as a research tool being somewhat limited by the fact that seldom are more than three to five factors considered in the database (e.g. macronutrient concentrations; a useful recent example is that of Ramakrishna et al., 2009) whereas the number of factors that can affect crop yield in practice runs well into double figures. In these instances DRIS has been more of a toy than a tool, but perhaps the greatest obstacle to the principles of DRIS being widely applied is the need for painstaking accumulation of a very large quantity of reliable data.

\section{Conclusions}

Given that the DRIS paradigm must still take root in modern agriculture what chance is there of its mutating into an ecological management tool? What kind of response variables are of most interest? In some situations vegetation cover is paramount, in others it is the prevalence of single or diverse species and in still others the greatest value lies in structure, e.g. grassland versus woodland or forest. There is potential for understanding natural ecosystems or habitats better by patiently accumulating data and developing norms in terms of which the condition of the habitat can be gauged and factors affecting the response variable of interest can be ranked in order of limiting importance.

\section{Acknowledgements}

The authors thank Professor Tertius de Wet of the Department of Statistics and Actuarial Science at the University of Stellenbosch for his advice. Financial support was received from Alcoa of Australia, Worsley Alumina Pty Ltd, the National Research Foundation (NRF) (Grant number FA2005040700027), BIOTA Southern Africa (sponsored by the German Federal Ministry of Education and Research under promotion number 01 LC 0024A), the Conservation Farming Project within the South African National Biodiversity Institute, the Global Environment Facility and the Mazda Wildlife Fund.

\section{References}

Beaufils, E.R. (1973) Diagnosis and recommendation integrated system (DRIS), Soil Science Bulletin, No. 1, University of Natal: Pietermaritzburg, South Africa.

Cade, B.S. and Noon, B.R. (2003) A gentle introduction to quantile regression for ecologists, Frontiers of Environment and Ecology, Vol. 1, pp. 412-420. 
Herselman, J.E. (2007) The concentration of selected trace metals in South African soils, University of Stellenbosch, South Africa, $\mathrm{PhD}$ thesis (unpublished).

Herselman, J.E., Steyn, C.E. and Fey, M.V. (2005) Baseline concentration of Cd, Co, Cr, Cu, Pb, Ni and Zn in surface soils of South Africa, South African Journal of Science, Vol. 101, pp. 509-512.

Jovanovic, N.Z., Adams, S., Thomas, A., Fey, M.V., Beekman, H.E., Campbell, R., Saayman, I. and Conrad, J. (2006) Improved DRASTIC method for assessment of groundwater vulnerability to generic aqueous-phase contaminants, In Waste Management and the Environment III, V. Popov, S. Kungolos, C.A. Brebbia and H. Itoh (eds), Wit Press, Southampton, UK, pp. 393-402.

Koenker, R. and Hallock, K.F. (2001) Quantile regression, Journal of Economic Perspectives, Vol. 15, pp. $143-156$.

Mills, A.J., Fey, M.V., Donaldson, J., Todd, S. and Theron, L. (2009) Infiltrability, plant cover and diversity: discovering abiotic-biotic relationships in a semi-arid shrubland using quantile regression, Plant and Soil, Vol. 320, pp. 321-332.

Mills, A.J., Fey, M.V., Gröngröft, A., Petersen, A. and Medinski, T.V. (2006) Unravelling the effects of soil properties on water infiltration: segmented quantile regression on a large data set from arid south-west Africa, Australian Journal of Soil Research, Vol. 44, pp. 783-797.

Mills, A.J. and Fey, M.V. (2004) A simple laboratory method for measuring the tendency of soils to crust, Soil Use and Management, Vol. 20, pp. 8-12.

Mwepu, M.M. (2007) Classification of South African soils in relation to their sorption of ionic solutes, University of Stellenbosch, South Africa, MSc Agriculture dissertation (unpublished).

Ramakrishna, A., Bailey, J.S. and Kirchhof, G. (2009) A preliminary diagnosis and recommendation integrated system (DRIS) model for diagnosing the nutrient status of sweet potato (Ipomoea batatas), Plant and Soil, Vol. 316, pp. 107-116.

Saayman, I.C., Beekman, H.E., Adams, S., Campbell, R.B., Conrad, J., Fey, M.V., Jovanovic, N., Thomas, A. and Usher, B.H. (2007) Assessment of aquifer vulnerability in South Africa WRC Rep. 1432/1/07, Water Research Commission, Pretoria, $92 \mathrm{p}$.

Schröder, H.K., Andersen, H.E. and Kiehl, K. (2005) Rejecting the mean: Estimating the response of fen plant species to environmental factors by non-linear quantile regression, Journal of Vegetation Science, Vol. 16, pp. 373-382.

Taylor, J.W. (2008) Estimating value at risk and expected shortfall using expectiles, Journal of Financial Econometrics, Vol. 6(2), pp. 231-252.

Walworth, J.L., Letzsch, W.S. and Sumner, M.E. (1986) Use of boundary lines in establishing diagnostic norms, Soil Science Society of America Journal, Vol. 50, pp. 123-128.

Walworth, J.L. and Sumner, M.E. (1987) The Diagnosis and Recommendation Integrated System (DRIS), B.A. Stewart (ed) Advances in Soil Science, Vol. VI, Springer-Verlag, New York, USA, pp. 149-188. 